\title{
Induction of retinoic acid receptor $\beta$ mediates growth inhibition in retinoid resistant human colon carcinoma cells
}

\author{
B Nicke, E-O Riecken, S Rosewicz
}

\begin{abstract}
Background-The molecular mechanisms underlying the differential sensitivity of human colon carcinoma cells to retinoid mediated growth inhibition are poorly understood.

Aim-To identify the intracellular mechanisms responsible for resistance against retinoid mediated growth inhibition in human colon carcinoma cells.

Methods-Anchorage independent growth of the human colon carcinoma cell lines HT29 and LoVo was determined by a human tumour clonogenic assay. Retinoid receptor expression was evaluated by reverse transcription polymerase chain reaction and northern blotting. Retinoid mediated transactivation was assessed by transient transfection of a pTK::ßREx2luc reporter construct. Retinoid receptor overexpression was achieved by selecting stably transfected cell clones.

Results-Retinoid treatment resulted in profound dose dependent growth inhibition in HT29 cells, while LoVo cells were unaffected. The two cell lines express identical patterns of nuclear retinoid receptor mRNA transcripts. However, on retinoid treatment, retinoic acid receptor $\beta$ gene expression was upregulated only in retinoid sensitive HT29 cells, but not in retinoid resistant LoVo cells. In accordance, stable overexpression of retinoic acid receptor $\beta$ but not $\alpha$ or $\gamma$ conferred retinoid mediated growth inhibition on LoVo cells.

Conclusion-Induction of retinoic acid receptor $\beta$ expression is required and sufficent to confer retinoid mediated growth inhibition on human colon carcinoma cells.

(Gut 1999;45:51-57)
\end{abstract}

Medizinische Klinik I, Gastroenterologie/ Infektiologie, Klinikum Benjamin Franklin, FU Berlin,

Hindenburgdamm 30, 12200 Berlin, Germany B Nicke

E-O Riecken

S Rosewicz

Correspondence to: Dr Rosewicz.

Accepted for publication 27 January 1999
Keywords: colon cancer; retinoic acid; retinoic acid receptor

Retinoids, the natural and synthetic derivatives of vitamin A, are known to regulate a broad spectrum of biological processes such as development, growth, and differentiation. ${ }^{12}$ Their clinical use has so far been focused on the treatment of promyelocytic leukaemia and some epithelial cancers ${ }^{3}$; in addition, retinoids are currently used as chemopreventive and therapeutic agents for a variety of other human premalignancies and tumours. ${ }^{1-4}$
The biological effects of retinoids are mainly mediated by two families of nuclear retinoic acid receptors (RARs), each consisting of three receptor subtypes designated $\alpha, \beta$, and $\gamma$ : the RARs and the retinoid X receptors (RXRs). ${ }^{56}$ In addition, each RAR gene generates multiple isoforms by either alternative splicing of exons or differential use of internal promoters. ${ }^{56}$ The two retinoid receptor families differ in their ligand binding affinities: the naturally occurring ligand for RARs in vivo is all-trans-retinoic acid (RA), whereas 9-cis RA preferentially binds to RXRs and RARs. ${ }^{7}$ Retinoid receptors are members of the steroid-thyroid hormone receptor superfamily and act as ligand activated transcription factors. RARs and RXRs modulate the expression of their target genes by interacting as either homodimers or heterodimers with cis-acting DNA elements, the so called RAREs (retinoic acid responsive elements) (reviewed $\mathrm{in}^{5}{ }^{6}$ ). Some of the target genes are RARs themselves, in particular the RAR $\beta$ gene, which contains an RARE ( $\beta$ RARE) in its promoter region. ${ }^{8} 9$ Autoinduction of the RAR $\beta$ gene has also been suggested to play a central role in mediating the cellular response to retinoic acid. The large spectrum of biological processes affected by retinoic acid as well as the tissue specific restricted expression of RAR/RXR subtypes during embryogenesis and in the adult organism suggests that each RAR and RXR subtype has a unique biological function and thereby determines whether a given cell or tissue is retinoid sensitive or resistant. ${ }^{10}$ Therefore detailed knowledge of the cell type specific expression pattern for each receptor subtype may provide a rationale for why certain malignancies or subgroups thereof are retinoid responsive whereas others are not.

In the colon, several experimental studies have looked at the potential antiproliferative effects of retinoids either in a chemopreventive setting of experimental colon carcinogenesis or as antiproliferative treatment of colon carcinoma cells in vivo and in vitro. ${ }^{11-19}$ The results of these studies have been quite contradictory; in the chemopreventive studies on colon carcinogenesis, promising activity ${ }^{13-15}$ as well as lack of biological activity ${ }^{112}$ of retinoids in preventing intestinal neoplasia have been reported. Similarily, retinoids have been shown

Abbreviations used in this paper: HTCA, human tumour clonogenic assay; RAR, retinoic acid receptor; RXR, retinoid X receptor; RA, retinoic acid; RT-PCR, reverse transcription polymerase chain reaction; RARE, retinoic acid responsive element. 
Table 1 Primers used for polymerase chain reaction amplification

\begin{tabular}{lll}
\hline & $5^{\prime}$ primer $\left(5^{\prime}-3^{\prime}\right)$ & 3'primer $\left(5^{\prime}-3^{\prime}\right)$ \\
\hline hRAR $\alpha$ & TGGGTGGACTCTCCCCGCCA & CACGCTGACGCCGGAGGTGGG \\
hRAR $\beta$ & CACTGGCTTGACCATCGCAGACC & CCTGGATCAATGCCACCTCTC \\
hRAR $\gamma$ & GGCCTGGGCCAGCCTGACCTC & CGTGCAGCTGGATCTGGGGCTG \\
hRXR $\alpha$ & ATGGCTGCCCCCTCGCTGCAC & GGCGCAGATGTGCTTGGTG \\
hRXR $\beta$ & ATGCCACCCCCGCCACTGGGC & GCCTCCAGGATCCTGTCCACAGGC \\
mRXR $\gamma$ & CCCCTGGTCACACTGGCTCGACG & CACCAGAGACCCAGGGCTGGTGG \\
\hline
\end{tabular}

to inhibit human colon carcinoma cell growth $^{16-18}$ or exert no antiproliferative effects. ${ }^{18} 19$ Taken together, these data suggest that distinct intracellular mechanisms may determine whether or not a given colon carcinoma cell will respond to the antiproliferative actions of retinoids. We know very little about the mechanisms that determine retinoid sensitivity in human colon cancer cells.

This study was therefore designed as an initial attempt to solve this problem. By using an in vitro system of a retinoid sensitive (HT29) and a retinoid resistant (LoVo) human colon carcinoma cell line, we now provide evidence that retinoid mediated induction of $\operatorname{RAR} \beta$ gene expression is sufficent to confer retinoid sensitivity on a retinoid resistant human colon carcinoma cell line.

\section{Materials and methods}

MATERIALS

Human colon carcinoma HT29 and LoVo cells were obtained from the American Type Tissue Culture Collection. Dulbecco's modified Eagle's medium was obtained from Gibco (Berlin, Germany), and Dulbecco's modified Eagle's medium/Ham's F12 medium and fetal calf serum from Biochrom (Berlin, Germany). $\left[\alpha-{ }^{32} \mathrm{P}\right] \mathrm{dCTP}(6000 \mathrm{Ci} / \mathrm{mmol})$ was from DuPont (Bad Homburg, Germany). Random priming labelling kit and blotting paper were purchased from Amersham (Braunschweig, Germany); RNA molecular size markers, random hexamer primers, and Moloney murine leukaemia virus reverse transcriptase were from BRL (Bethesda, Maryland, USA); restriction enzymes were from Boehringer Mannheim (Mannheim, Germany); Thermus aquaticus (Taq) DNA polymerase was from Promega (Heidelberg, Germany). All retinoids were kindly provided by Hofmann-LaRoche (Basel, Switzerland). All other chemicals were of analytical grade and purchased from Sigma (Deisenhofen, Germany).

\section{CELL CULTURE}

Both cell lines were grown as subconfluent monolayer cultures supplemented with $10 \%$ $(\mathrm{v} / \mathrm{v})$ fetal calf serum, penicillin $(100 \mathrm{U} / \mathrm{ml})$, and streptomycin $(100 \mathrm{U} / \mathrm{ml})$. The cells were kept under $95 \%$ air and $5 \% \mathrm{CO}_{2}$ at $37^{\circ} \mathrm{C}$. Medium was changed every two days. Retinoids were prepared under subdued light as stock solutions in dimethyl sulphoxide and aliquots were kept stored at $-80^{\circ} \mathrm{C}$ until used. Retinoids were added to the cultures from stock solutions. Control cells received the same amount of dimethyl sulphoxide, and the final concentration of dimethyl sulphoxide in the medium never exceeded $0.1 \%$. Cell viability was routinely checked by the trypan blue exclusion test and was consistently found to be greater than $95 \%$.

HUMAN TUMOUR CLONOGENIC ASSAY (HTCA)

For evaluation of anchorage independent clonal growth, we used a methylcellulose HTCA exactly as previously described. ${ }^{20} \mathrm{Vi}-$ ability of the cells had to be more than $85 \%$ before they were used for an experiment. The final incubation mixture contained the final retinoid concentrations indicated in the Results section, thus tumour cells were exposed to retinoids for the complete assay period. Colony formation was evaluated with an inverted microscope after an incubation period of 10 days at $37^{\circ} \mathrm{C}$, pH 7.2 , and $5 \% \mathrm{CO}_{2}$. Only colonies containing more than 20 cells were counted.
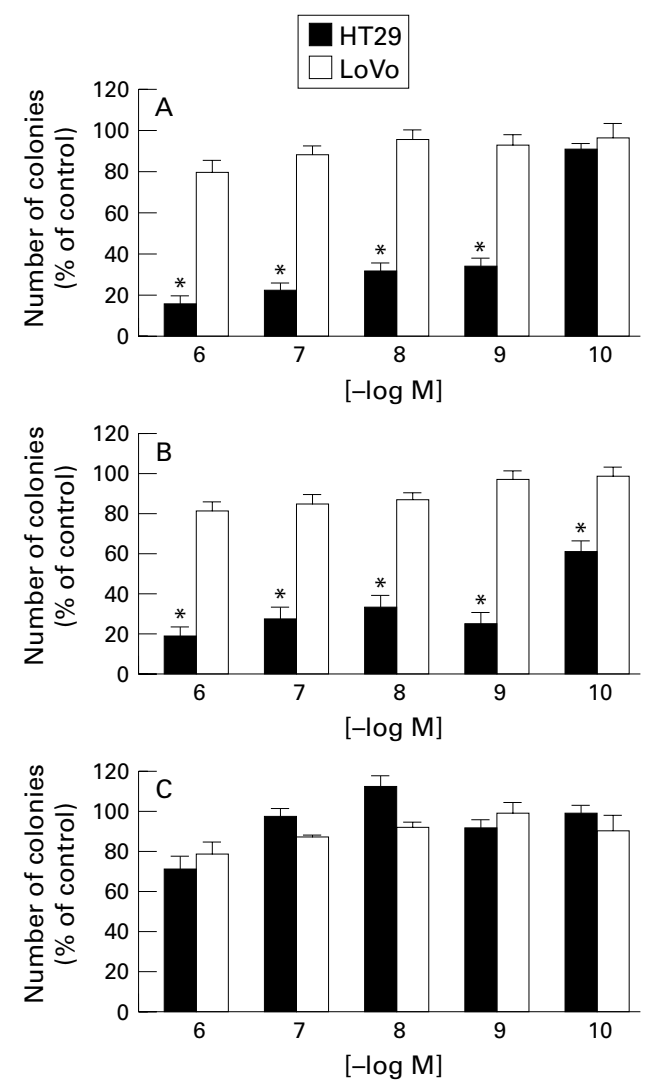

Figure 1 Differential effects of retinoid derivatives on anchorage independent growth. HT29 and LoVo cells were analysed using the human tumour clonogenic assay with the indicated final concentrations of each retinoid analogue ( $A$, all-trans-retinoic acid; $B, 13$-cis-retinoic acid; $C$, 9-cis-retinoic acid). After 10 days the number of colonies was evaluated and expressed as percentage of vehicle treated controls. Values are mean (SEM) from three independent experiments, each performed in triplicate. ${ }^{*} p<0.05 v$ controls. 
A
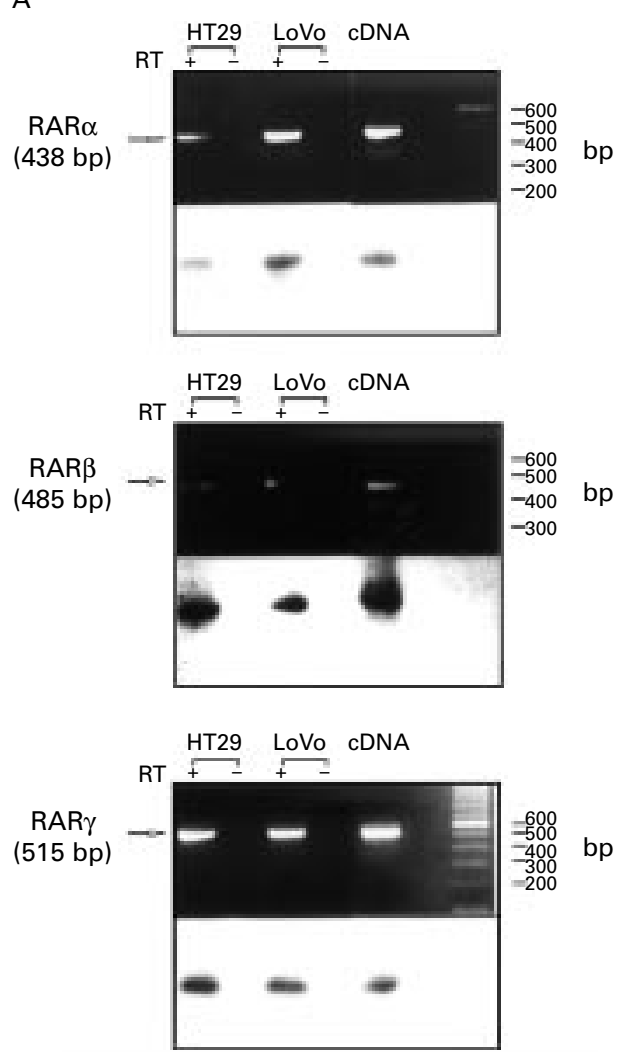

B
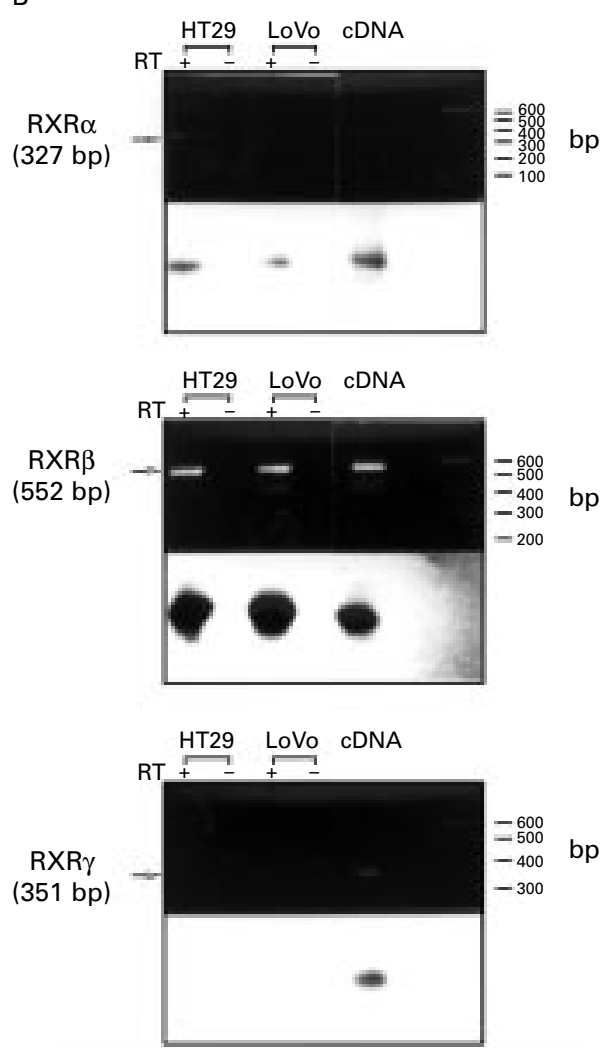

Figure 2 Identical expression of nuclear retinoid receptors in HT29 and LoVo cells. Reverse transcription polymerase chain reaction (RT-PCR) analysis was performed on HT29 and LoVo cells using receptor specific oligonucleotide primers. The respective receptor subtype $c D N A$ was used as a positive internal control. RT-PCR with ( + ) or without (-) prior reverse transcription (the latter served as a negative internal control) was performed. Duplicate aliquots from each RT-PCR product were electrophoresed through a $1 \%$ agarose gel and then subjected to Southern blot analysis using the respective cDNA probes for the retinoic acid receptors (RARs)/retinoid X receptors (RXRs) to ensure specificity of the amplification product. Size determination was performed using a DNA ladder. (A) RT-PCR for RARs; (B) RT-PCR for RXRs.

REVERSE TRANSCRIPTION POLYMERASE CHAIN REACTION (RT-PCR) ANALYSIS

RNA was isolated exactly as previously described. ${ }^{20}$ Reverse transcription was performed using $1 \mu \mathrm{g}$ total RNA, $100 \mathrm{pM}$ random hexamer primer, $1 \mathrm{mM}$ dithiothreitol, $6 \mathrm{mM}$ $\mathrm{Mg}^{2+}, 500 \mu \mathrm{M}$ each dNTP, 20 units RNAsin (Promega, Heidelberg, Germany), and Moloney murine leukaemia virus reverse transcriptase. The reverse transcriptase mixture was used directly as a template for PCR in a 1:20 dilution. Table 1 shows the receptor subtype specific 5' primers and 3' primers used for amplification; they were designed complementary to the human and mouse nucleotide sequences. The expected molecular size of the PCR amplification products was as follows: RAR $\alpha, 438$ bp; RAR $\beta, 435$ bp; RAR $\gamma, 515$ bp; RXR $\alpha, 327$ bp; RXR $\beta, 552$ bp; RXR $\gamma, 351$ bp. The reaction was carried out exactly as previously described. ${ }^{20}$

SOUTHERN BLOT ANALYSIS

After amplification, $10 \mu \mathrm{l}$ of each RT-PCR mixture was subjected to electrophoresis on a $1.5 \%$ agarose gel. Southern blotting was performed exactly as previously described. ${ }^{20}$ The following plasmids were used: pSG5:RAR $\alpha$ containing a $1.9 \mathrm{~kb}$ EcoRI fragment coding for human $\mathrm{RAR} \alpha^{21}$; pSG5:RAR $\beta$ containing a $1.4 \mathrm{~kb}$ EcoRI-
BamHI fragment coding for human RAR $\beta^{22}$; pSG5:RAR $\gamma$ containing a $1.6 \mathrm{~kb}$ EcoRI fragment coding for human $\operatorname{RAR} \gamma^{21}$; pSG5:RXR $\alpha$ containing a $1.8 \mathrm{~kb}$ EcoRI fragment coding for mouse $\mathrm{RXR} \alpha^{23}$; pTL1 containing a $1.35 \mathrm{~kb}$ EcoRI-HindIII fragment coding for mouse $\mathrm{RXR} \beta^{23}$; $\mathrm{pSG} 5: \mathrm{RXR} \gamma$ containing a $1.5 \mathrm{~kb}$ EcoRI fragment coding for mouse RXR $\gamma .{ }^{23}$ Hybridisation was carried out as previously described. ${ }^{20}$

\section{TRANSACTIVATION ASSAYS}

The pTK::ßREx2-luc reporter construct contains two tandem copies of the RARE of the human RAR $\beta$ promoter under the control of the herpes virus thymidine kinase promoter linked to the luciferase reporter gene. ${ }^{24}$ For transient transfections, colon carcinoma cell lines were transfected with $5 \mu \mathrm{g}$ of reporter construct plasmid using the Lipofectamine reagent (Gibco-BRL, Eggenstein, Germany) for six hours under serum free conditions. After 12 hours, the indicated concentrations of retinoids or vehicle were added and the mixture incubated for an additional 24 hours. Luciferase activity of cell lysates was then determined using a luciferase assay system (Promega, Heidelberg, Germany). Luciferase activity was expressed as fold induction of vehicle treated control cells. 


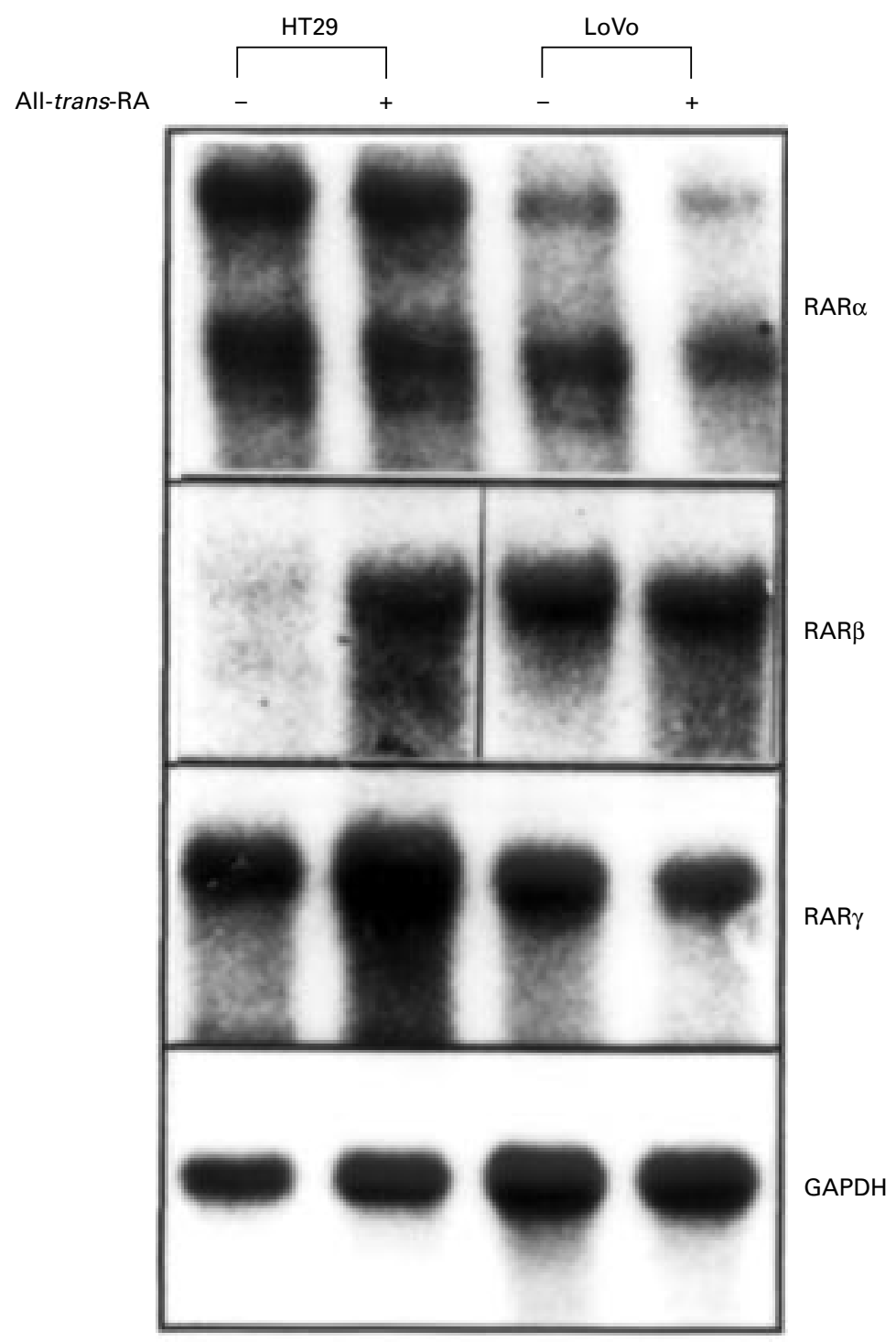

Figure 3 Differential autoregulation of retinoic acid receptor (RAR) $\beta$ by retinoids. HT29 and LoVo cells were incubated with vehicle or $10 \mu \mathrm{M}$ all-trans-retinoic acid (all-trans $R A$ ) for 24 hours. Then $25 \mu \mathrm{g}$ total $R N A$ was analysed by northern blotting using radioactively labelled cDNAs specific for the RAR subtypes. The blots were then stripped and rehybridised with glyceraldehyde-3-phosphate dehydrogenase (GAPDH) cDNA to ensure equal RNA loading. The results shown are representative of three independent experiments.

STABLE TRANSFECTION OF COLON CARCINOMA CELLS

Full length cDNAs of human $\operatorname{RAR} \alpha, \beta$, and $\gamma$ were isolated from the host vector pSG5 and subcloned in the linearised HindIII site of $\mathrm{pRc} /$ $\mathrm{CMV}$ vector, containing a neomycin resistance gene. This yielded the RAR cDNAs preceded by the CMV promoter and followed by the human growth hormone termination and polyadenylation signal. The constructs were confirmed by restriction analysis. HT29 and LoVo carcinoma cell lines (about $4 \times 10^{6}$ cells per $100 \mathrm{~mm}$ dish) were transfected with $5 \mu \mathrm{g}$ of each plasmid using the Lipofectamine reagent following the instructions supplied by the manufacturer. Control cells were transfected with vector alone (mock transfected) not containing RAR specific nucleotide sequences. At 24 hours after transfection, cells were diluted 1:10 and plated in medium containing

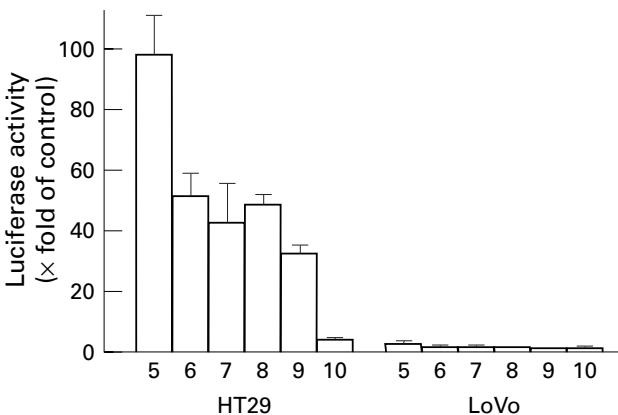

All-trans-retinoic acid [- $\log \mathrm{M}]$

Figure 4 Differential effects of all-trans-retinoic acid on transactivation. HT29 and LoVo cells were transiently transfected with the pTK:: $\beta R E \times 2$-luc reporter construct. After incubation with the indicated concentrations of all-trans $R A$ for 24 hours, luciferase activity was determined and expressed as fold increase over basal (luciferase activity in the absence of retinoids). Values are mean (SEM) from six independent experiments, each performed in triplicate wells.

$1 \mathrm{mg} / \mathrm{ml} \mathrm{G} 418$. Resistant cell clones appeared after about 21 days and were picked for expansion at 35 days. The RAR and mock transfected cell clones were kept under selection pressure for all the experiments.

STATISTICAL ANALYSIS

Results were evaluated statistically by analysis of variance followed by a multiple contrast test. $\mathrm{p}<0.05$ was considered to be significant.

\section{Results}

DIFFERENTIAL EFFECTS OF RETINOIDS ON HUMAN COLON CARCINOMA CELL GROWTH

We initially investigated the antiproliferative effects of the major naturally occurring retinoid derivatives on anchorage independent growth in HT29 and LoVo cells. Using HTCA, we observed profound dosedependent growth inhibition in response to all-trans and 13-cis RA in HT29 cells, whereas 9-cis RA treatment resulted in significant growth inhibition only at a maximal concentration of $1 \mu \mathrm{M}$ (fig 1 ). In contrast, none of the retinoids tested had any significant growth inhibitory effect on LoVo cells over the concentration range $100 \mathrm{pM}$ to $1 \mu \mathrm{M}$ (fig 1 ), suggesting that this cell line is completely retinoid resistant in terms of anchorage independent growth regulation. This in vitro model of a retinoid sensitive and retinoid resistant colon carcinoma cell line should therefore be suitable for studying the intracellular mechanisms that determine sensitivity for retinoid mediated growth inhibition.

\section{IDENTICAL EXPRESSION PATTERN OF NUCLEAR} RETINOID RECEPTORS

Different expression patterns of various nuclear receptor subtypes may account for the differential retinoid mediated growth regulation in HT29 and LoVo cells. To investigate this hypothesis, we performed RT-PCR using receptor subtype specific primers and confirmed the specificity of the amplification product by subsequent Southern blotting using the respective receptor subtype cDNA. To exclude amplification of genomic DNA, an 
A

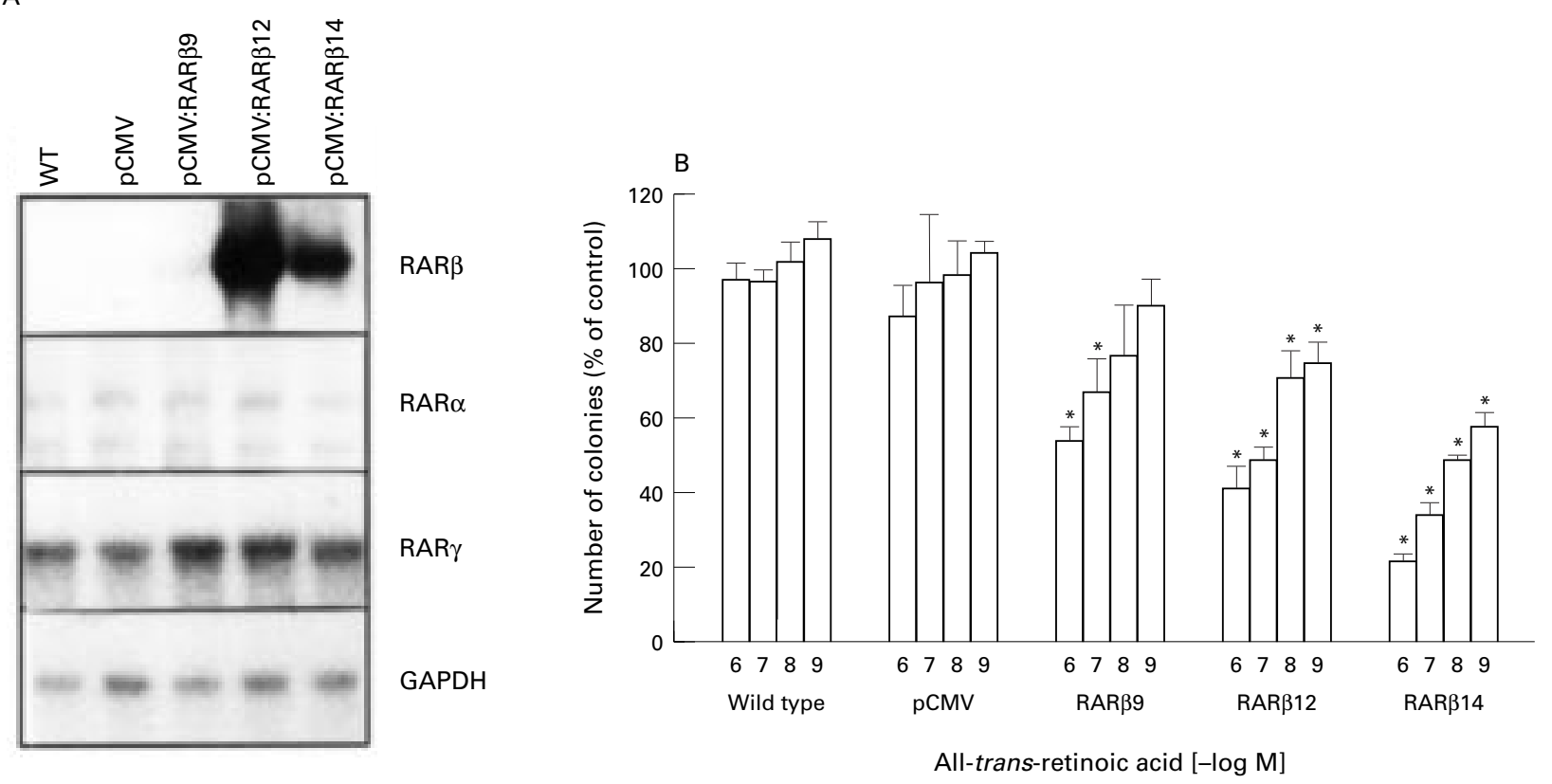

Figure 5 Overexpression of retinoic acid receptor (RAR) $\beta$ restores retinoid sensitivity in LoVo cells. After stable transfection with the RAR $\beta$ cDNA, overexpression of RAR $\beta$ mRNA was confirmed by northern blotting $(A)$. GAPDH, Glyceraldehyde-3-phosphate dehydrogenase. Transfected

( $P C M V: R A R \beta 9, p C M V: R A R \beta 12, p C M V: R A R \beta 14)$, mock transfected ( $p C M V)$, and wild type (WT) LoVo cells were then analysed by human tumour clonogenic assay using the indicated concentrations of all-trans-retinoic acid. (B) After 10 days the number of colonies was evaluated and expressed as a percentage of vehicle treated contols. Results shown are mean (SEM) from three independent experiments, each performed in triplicate. ${ }^{\star} p<0.05 v$ controls.

internal control without prior reverse transcription was performed and consistently found to be negative. To our surprise, however, we observed that the two cell lines expressed identical patterns of retinoid receptors: mRNA transcripts for $\operatorname{RAR} \alpha, \beta$, and $\gamma$ as well as $\operatorname{RXR} \alpha$ and $\beta$ could be shown repeatedly in both cell lines (fig 2A,B). Furthermore, $\operatorname{RXR} \alpha$ and $\beta$ were also present in both cell lines, whereas mRNA transcripts for $\mathrm{RXR} \gamma$ could not be detected in either cell line (fig 2B). Therefore, differential expression of retinoid receptor subtypes cannot be responsible for the observed differences in retinoid sensitivity between HT29 and LoVo cells.

LACK OF RETINOID MEDIATED RAR $\beta$ INDUCTION IN LOVO CELLS

Retinoid mediated autoinduction of $\operatorname{RAR} \beta$ gene expression has been suggested to play a crucial role in mediating the biological effects of retinoids. We therefore investigated the effects of all-trans RA on RAR subtype gene expression in both cell lines using northern blot analysis. Incubation with all-trans RA for 24 hours resulted in a selective pronounced increase in RAR $\beta$ mRNA concentrations in HT29 cells while RAR $\alpha$ and $\gamma$ mRNA levels remained unchanged (fig 3). In contrast, incubation with all-trans RA had no effect on RAR $\beta$ mRNA concentrations in the retinoid resistant LoVo cell line (fig 3). To confirm further the suspected defect in retinoid mediated autoinduction of the RAR $\beta$ gene in LoVo cells, we performed transactivation assays using the pTK::ßREx2-luc reporter construct transiently transfected into both cell lines (fig 4). All-trans RA treatment of HT29 cells resulted in a pronounced dose dependent transactivation of the reporter construct, with an approximately 100- fold transcriptional increase mediated by the RARE of the human RAR $\beta$ gene. In contrast, all-trans RA treatment of LoVo cells did not result in a significant transactivation of the reporter construct, further corroborating the observation that the pathway of retinoid mediated autoinduction of the RAR $\beta$ gene is defective in retinoid resistant LoVo cells (fig 4).

OVEREXPRESSION OF RAR $\beta$ RESTORES RETINOID SENSITIVITY IN LOVO CELLS

We next investigated whether the lack of retinoid mediated $\operatorname{RAR} \beta$ induction is indeed responsible for retinoid resistance in LoVo cells. We therefore stably transfected the RAR $\beta$ cDNA in LoVo cells and examined the consequences of $\operatorname{RAR} \beta$ overexpression using HTCA. Three independent cell clones (pCMV:RAR $\beta 9,12$, and 14) with significant RAR $\beta$ mRNA overexpression compared with mock transfected controls or wild type parental cells were obtained, as evidenced by northern blotting (fig 5). Overexpression of RAR $\beta$ did not result in changes in RAR $\alpha$ or $\gamma$ mRNA expression in the transfected cell clones. When these RAR $\beta$ overexpressing LoVo cell clones were incubated with all-trans RA in HTCAs, we observed significant dose dependent growth inhibition of all three cell clones, whereas wild type and mock transfected controls were unaffected (fig 5). To confirm the specificity of the effect mediated by RAR $\beta$ overexpression, we also overexpressed RAR $\alpha$ and $\gamma$ in LoVo cells. We obtained two stably RAR $\alpha$ and one RAR $\gamma$ overexpressing cell clones, as evidenced by northern blotting (fig 6). However, when these stably transfected cell lines were analysed by HTCA, no significant retinoid mediated growth inhibition was observed compared with wild type or mock transfected controls (fig 6). 
A
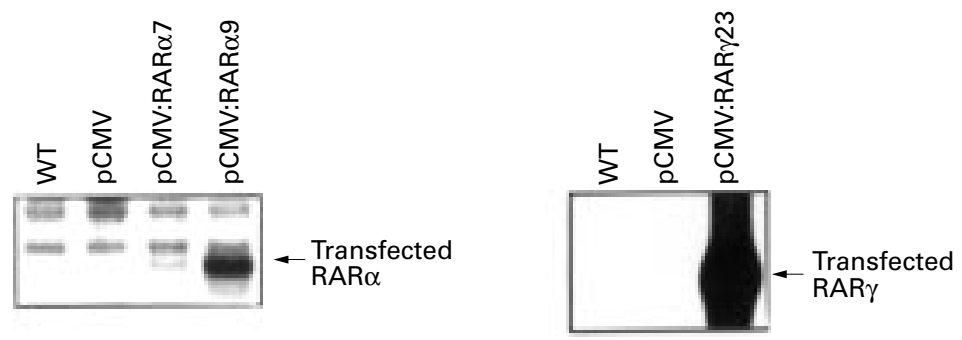

B

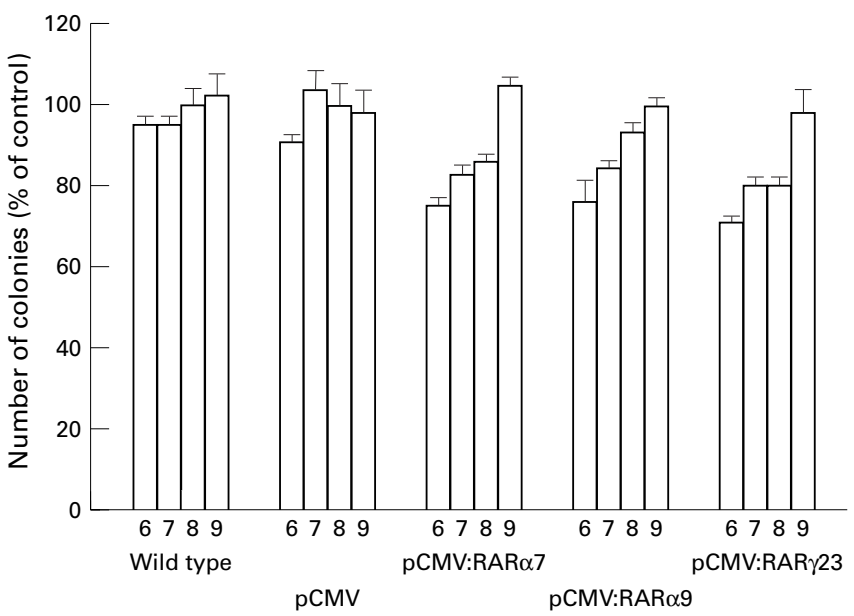

All-trans-retinoic acid [-log $\mathrm{M}]$

Figure 6 Overexpression of retinoic acid receptor $(R A R) \alpha$ or $\gamma$ does not restore retinoid sensitivity in LoVo cells. After stable transfection with the RARa and $\gamma \mathrm{cDNA}$, overexpression of the respective RAR subtype $m R N A$ was confirmed by northern blotting (A). Transfected ( $p C M V: R A R a 7, p C M V: R A R a 9, p C M V: R A R \gamma 23)$, mock transfected ( $p C M V)$, and wild type (WT) LoVo cells were then analysed by human tumour clonogenic assay using the indicated concentrations of all-trans-retinoic acid. (B) After 10 days the number of colonies was evaluated and expressed as a percentage of vehicle treated contols. Results shown are mean (SEM) from three independent experiments, each performed in triplicate.

These data therefore indicate that RAR $\beta$ overexpression selectively and specifically confers retinoid mediated growth inhibition on retinoid resistant LoVo cells.

\section{Discussion}

On the basis of their antiproliferative mechanism of action and the low toxicity profile in clinical studies, retinoids represent an attractive therapeutic approach for chemoprevention and treatment of malignancies. ${ }^{1-4}$ Accordingly, a variety of different retinoids were investigated in a series of preclinical models of colon carcinogenesis and cancer. The emerging picture from these studies is that some colonic cancer cells will respond to antiproliferative treatment with retinoids while others are resistant to growth inhibition. ${ }^{11-19}$ Although much has been learnt over the last few years about the underlying molecular mechanisms of retinoid action, there is currently no information available on the differential retinoid sensitivity of colon cancer cells. In this study we therefore established an in vitro system of two human colon cancer cell lines (HT29 and LoVo) as a model for further investigation of differential response to retinoid mediated growth inhibition.
Anchorage independent growth inhibition was analysed by an HTCA, which has been shown to reflect more reliable growth regulatory phenomena in vitro with tumour growth regulation in vivo. ${ }^{25}$ We tested three therapeutically relevant retinoid derivatives for their ability to inhibit anchorage independent growth in both human colon carcinoma cell lines. Alltrans and 13-cis RA treatment resulted in profound dose dependent growth inhibition at therapeutically achievable concentrations ${ }^{26}$ in HT29 cells, whereas the RXR family, which prefers the ligand 9-cis RA, was mainly ineffective. In contrast, even at maximal concentrations, none of the retinoids tested had antiproliferative effects on LoVo cells, suggesting that this cell line is indeed resistant to retinoid mediated growth inhibition.

Assuming that each retinoid receptor subtype exerts a unique biological function, as supported by several studies, ${ }^{27-31}$ it is conceivable that a different retinoid receptor expression pattern in LoVo cells accounts for the lack of biological effects in this cell line. However, RT-PCR analysis using retinoid receptor subtype specific primers showed that the two cell lines express identical repertoires of RARs $(\alpha$, $\beta, \gamma$ ) and RXRs ( $\alpha$ and $\beta$ ), and RXR $\gamma$ was not expressed in either cell line. Therefore it appears unlikely that lack of expression of certain retinoid receptor subtypes is responsible for retinoid resistance in LoVo cells.

Recent studies suggested that retinoid mediated autoinduction of the endogenous RAR $\beta$ gene may play a crucial role in mediating growth inhibition in various cell types. ${ }^{32-34}$ In fact, when retinoid sensitive HT29 cells were incubated with all-trans RA for 24 hours, selective autoinduction of RAR $\beta$ gene expression was observed, whereas RAR $\alpha$ and $\gamma$ mRNA concentrations remained unchanged. In contrast, no autoinduction of RAR $\beta$ gene expression was observed under identical experimental conditions in the retinoid resistant LoVo cell line. These data were further substantiated by transactivation assays using a human $\beta$ RAREluciferase reporter construct. Again, treatment with all-trans RA resulted in potent transcriptional activation (nearly 100-fold) of the reporter construct in HT29 cells, whereas no significant transactivation was observed in LoVo cells. The reasons for the lack of RAR $\beta$ autoinduction in retinoid resistant LoVo cells are not known. A similar observation has been made in several pituitary cell lines without evidence of mutations in the RAR $\beta$ promoter, ${ }^{34}$ suggesting either a general defect in the transcriptional machinery ${ }^{32}{ }^{33}$ or different expression of cell type specific factors required for retinoid responsiveness. In this context it has recently been shown that E1A-like proteins act as coactivators of retinoid dependent transcriptional activation of the $\operatorname{RAR} \beta$ promoter. $^{35}{ }^{36}$ Whether lack of expression or misfunction of these proteins is responsible for the failure to autoinduce RAR $\beta$ in LoVo cells is under investigation.

To determine further the biological significance of RAR $\beta$ autoinduction by retinoids (or lack thereof), we generated three independent 
LoVo cell clones that stably overexpress $\operatorname{RAR} \beta$ mRNA. When these cell clones were analysed by HTCA, significant dose dependent growth inhibition by all-trans RA was observed in contrast with the wild type parental or mock transfected control cells which were not responsive to retinoid. To substantiate further the specificity of $\operatorname{RAR} \beta$ overexpression in mediating retinoid responsiveness, we also generated LoVo cell clones overexpressing RAR $\alpha$ and RAR $\gamma$. However, although significant overexpression of both receptor subtypes could be shown by northern blotting, neither RAR $\alpha$ nor $\operatorname{RAR} \gamma$ conferred retinoid responsiveness on LoVo cells in HTCAs. These data therefore indicate that induction of RAR $\beta$ gene expression is required, and is sufficent, to confer retinoid mediated growth inhibition on otherwise retinoid resistant LoVo colon carcinoma cells. In addition to this study, it has recently been shown that RAR $\alpha$ confers retinoid sensitivity on human breast cancer cells, ${ }^{31} \operatorname{RAR} \gamma$ mediates growth inhibition in teratocarcinomas and neuroblastoma cells, ${ }^{27}{ }^{28}$ and $\operatorname{RXR} \beta$ determines retinoic acid responsive gene regulation in embryonal cells ${ }^{29}$ Taken together, these observations suggest that the biological function of each retinoid receptor subtype depends on the tissue specific context and has to be determined individually for each cell type.

In summary, our study provides for the first time an experimental model that may explain the differential responsiveness to retinoid mediated growth inhibition previously observed in a variety of preclinical models of colon carcinogenesis and cancer. The ability of a given colon carcinoma tissue to autoinduce RAR $\beta$ gene expression on retinoid treatment may be exploited as a predictive variable to evaluate an antiproliferative response to retinoid treatment.

This work was supported by a grant from the Deutsche Krebshilfe (10-0954-Ro2) and the Maria Sonnenfeld Gedächtnisstiftung. We are grateful to Dr R Evans (Salk Institute, San Diego, CA, USA) for the pTK:: $\beta$ REx2-luc construct and Dr P Chambon (Strasbourg, France) for the retinoid receptor plasmids.

1 Bollag W, Holdener EE. Retinoids in cancer prevention and therapy. Ann Oncol 1992;3:512-26.

2 Gudas LJ, Sporn MB, Roberts AB. Cellular biology and biochemistry of the retinoids. In: Sporn MB, Roberts AB Goodman DS, eds. The retinoids. 2nd edn. New York: Raven Press, 1994:443-520.

3 Tallman MS, Wiernik PH. Retinoids in cancer treatment. $\mathcal{F}$ Clin Pharmacol 1992;32:868-88.

4 Lippman SM, Heyman RA, Kurie JM, et al. Retinoids and chemoprevention: clinical and basic studies. 7 Cell Biochem 1995;22(suppl): 1-10.

5 Giguere V. Retinoic acid receptors and cellular retinoid binding proteins: complex interplay in retinoid signaling. Endocr Rev 1994;15:61-79.

6 Leid M, Kastner P, Chambon P. Multiplicity generates diversity in the retinoic acid pathway. Trends Biol Sci 1992; diversity in

7 Heyman RA, Mangelsdorf, DJ, Dyck JA, et al. 9-cis retinoic acid is a high affinity ligand for the retinoid X receptor. Cell 1992;68:397-406.

8 de The H, Vivanco-Ruiz MDM, Tiollais P, et al. Identification of a retinoic acid response element in the retinoic acid receptor $\beta$ gene. Nature 1990;343:177-80

9 Hoffmann B, Lehmann JM, Zhang X-K, et al. A retinoic acid receptor-specific element controls the retinoic acid receptor $\beta$ promoter. Mol Endocrinol 1990;4:1734-43.

10 Dolle P, Ruberte E, Leroy P, et al. Retinoic acid receptors and cellular retinoid binding proteins. A systematic study of their differential pattern of transcription during mouse organogenesis. Development 1990;110:1133-51.
11 Ward JM, Sporn MB, Wenk ML, et al. Dose response to intrarectal administration of $\mathrm{N}$-methyl-N-nitrosurea and histopathologic evaluation of the effects of two retinoids on colon lesions in rats. F Natl Cancer Inst 1978;60:1489-93.

12 Wenk ML, Ward JM, Reznik G, et al. Effects of three retinoids on colon adenocarcinomas, sarcomas and hyperplastic polyps induced by intrarectal $\mathrm{N}$-methyl-N-nitrosurea administration in male F344 rats. Carcinogenesis 1981;2: 1167-72.

13 Kawamori T, Tanaka T, Suzui M, et al. Chemoprevention of azoxymethane-induced intestinal carcinogenesis by a novel synthesized retinoidal butenolide, 5-hydroxy-4-(2-phenyl(E)-ethenyl)-2(5H)-furanone, in rats. Carcinogenesis 1995; 16:795-800

14 Stopera SA, Bird RP. Effects of all-trans retinoic acid as a potential chemopreventive agent on the formation of azoxymethane-induced aberrant crypt foci: differential expression of c-myc and c-fos mRNA and protein. Int $\mathcal{F}$ Cancer 1993;53:798-804

15 O'Dwyer PJ, Ravikumar TS, McCabe DP, et al. Effect of 13-cis retinoic acid on tumor prevention, tumor growth, and metatasis in experimental colon cancer. F Surg Res 1987;43:550-7.

16 Philips RW, Kikendall JW, Luk GD, et al. $\beta$-carotene inhibits rectal mucosa ornithine decarboxylase activity in colon cancer patients. Cancer Res 1993;53:3723-5.

17 Liepkalns VA, Icard-Liepkalns C. Retinoic acid induced augmentation of molecular species carrying sialosyl Lewis ${ }^{\mathrm{a}}$ antigen in colorectal carcinoma cell cultures. Int $\mathcal{F}$ Cancer antigen in colorectal

18 Niles RM, Wilhelm SA, Thomas P, et al. The effect of sodium butyrate and retinoic acid on growth and CEA production in a series of human colorectal tumor cell lines representing different states of differentiation. Cancer Invest $1988 ; 6: 39-45$.

19 Kane K, Langman MJS, Willims GR. Antiproliferative responses of two human colon cancer cell lines to vitamin $\mathrm{D}_{3}$ are differentially modified by 9 -cis retinoic acid. Cancer Res 1996;56:623-32.

20 Rosewicz S, Stier U, Brembeck F, et al. Retinoids: effects on growth, differentiation and nuclear receptor expression in human pancreatic carcinoma cell lines. Gastroenterology 1995;109:1646-60.

21 Petkovich M, Brand NJ, Krust A, et al. A human retinoic acid receptor which belongs to the family of nuclear receptors. Nature 1987;330:444-50.

22 Brand N, Petkovich A, Krust A, et al. Identification of a second human retinoic acid receptor. Nature 1988;332:850-3.

23 Leid M, Kastner P, Lyons R, et al. Purification, cloning, and RXR identity of the HeLa cell factor with which RAR or TR heterodimerizes to bind target sequences efficiently. Cell 1992;68:377-95.

24 Forman BM, Umesono K, Chen J, et al. Unique response pathways are established by allosteric interactions among nuclear hormone receptors. Cell 1995;81:541-50.

25 Folkman J, Moscona A. Role of cell shape in growth control. Nature 1978;273:345-9

26 Muindi JRF, Frankel SR, Huselton C, et al. Clinical pharmacology of oral all-trans retinoic acid in patients with acute promyelocytic leukemia. Cancer Res 1992;52:213842

27 Moasser MM, DeBlasio A, Dmitrovsky E. Response and resistance to retinoic acid are mediated through the retinoic acid receptor $\gamma$ in human teratocarcinomas. Oncogene 1994;9:833-40.

28 Marshall GM, Cheung B, Stacey KP, et al. Increased retinoic acid receptor gamma expression suppresses the malignant phenotype and alters differentiation potential of human neuroblastoma cells. Oncogene 1995;11:485-91.

29 Minucci S, Zand DJ, Dey A, et al. Dominant negative retinoid $\mathrm{X}$ receptor $\beta$ inhibits retinoic acid-responsive gene regulation in embryonal carcinoma cells. Mol Cell Biol 1994;14:360-72.

30 Lee X, Si SP, Tsou HC, et al. Cellular aging and transformation suppression: a role for retinoic acid receptor $\beta_{2}$. Exp Cell Res 1995;218:296-304.

31 van der Leede BM, Folkers GE, van den Brink CE, et al. Retinoic acid receptor $\alpha_{1}$ isoform is induced by estradiol and confers retinoic acid sensitivity in human breast cancer cells. Mol Cell Endocrinol 1995;109:77-86.

32 Liu Y, Lee MC, Wang HG, et al. Retinoic acid receptor $\beta$ mediates the growth-inhibitory effect of retinoic acid by promoting apoptosis in human breast cancer cells. Mol Cell Biol 1996;16:1139-49.

33 Zhang XK, Liu Y, Lee MO, et al. A specific defect in the retinoic acid response associated with human lung cancer cell lines. Cancer Res 1994;54:5663-9.

34 Davis KD, Lazar MA. Induction of retinoic acid receptor $\beta$ by retinoic acid is cell specific. Endocrinology 1993;132: 1469-74.

35 Berkenstam A, Ruiz MD, Ruiz MV, et al. Cooperativity in transcription between retinoic acid receptor and TFIID requires an activity analogous to E1A. Cell 1992;69:40112.

36 Kruyt FA, Folkers GE, Walhout AJM, et al. E1A functions as a coactivator of retinoic acid-dependent retinoic acid receptor- $\beta$ promoter activation. Mol Endocrinol 1993;7: 604-15. 